\section{PKS}

PUBLIC KNOWLEDGE PROJECT
REVISTA DE

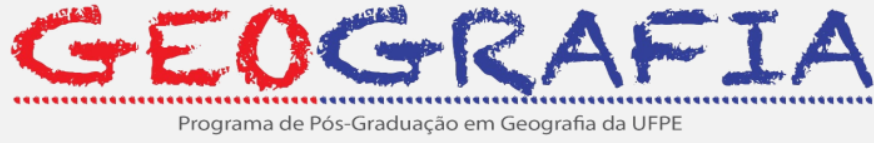

https://periodicos.ufpe.br/revistas/revistageografia
OJS

OPEN JOURNAL SYSTEMS

\title{
POVOS INDÍGENAS EM DOURADOS-MS: REFLEXÕES GEOGRÁFICAS A PARTIR DE NOTÍCIAS DE JORNAIS
}

\author{
Mateus Janú de Lima ${ }^{1}$, Yuri Gabriel Vieira Além²
}

\begin{abstract}
${ }^{1}$ Mestrando no Programa de Pós-Graduação em Geografia, Universidade Federal da Grande Dourados (UFGD). E-mail: mateus.janudelima@gmail.com, Orcid: http://orcid.org/0000-0002-8916-8701

${ }^{2}$ Mestrando no Programa de Pós-Graduação em Geografia, Universidade Federal da Grande Dourados (UFGD). E-mail: alemyuri@gmail.com,Orcid: https://orcid.org/0000-0002-1272-1425
\end{abstract}

Artigo recebido em 06/07/2021 e aceito em 18/09/2021

\begin{abstract}
RESUMO
A cidade de Dourados - Mato Grosso do Sul, e a região à qual ela pertence, são conhecidas como celeiros do agronegócio. Junto a essa imagem agroexportadora muito aclamada por alguns setores da sociedade, existe uma série de realidades que complexificam o que parece ser simples, uniforme e resolvido. $\mathrm{O}$ progresso capitalista se defronta com a existência de povos indígenas e seus modos distintos de existirem, e o resultado é um conjunto de relações, embates, contradições e distopias. Procuramos adentrar essa complexidade analisando três notícias de jornais digitais locais, relacionadas a situações envolvendo indígenas. A partir delas buscamos captar elementos que servissem como articuladores para reconhecimento do contexto geográfico. Nessa correlação de interesses e lutas travadas diariamente de formas múltiplas, de um lado há povos resistindo e de outro forças modernizadoras tentando os exterminar ou assimilar. A história de Dourados corre junto à história desses conflitos, por mais que as narrativas hegemônicas afirmem o contrário. As situações geográficas cotidianas nos mostram isso. As narrativas hegemônicas também tentam tirar dos indígenas a condição de sujeitos, e imprimi-los numa condição espacial passiva. Todavia, os povos indígenas mostram diariamente que existem ainda hoje porque conquistaram isso no decorrer do espaço e do tempo, com suas estratégias, negociações, erros e acertos.
\end{abstract}

Palavras-chave: Povos indígenas; Guarani-kaiowá; Colonialidade.

\section{INDIGENOUS PEOPLE IN DOURADOS-MS: GEOGRAPHIC REFLECTIONS BASED ON NEWSPAPER NEWS}

\begin{abstract}
The city of Dourados - Mato Grosso do Sul and the region to which it belongs are known as the granaries of agribusiness. Along with this agro-exporting image much-acclaimed by some sectors of society, there is a series of realities that complexify what seems to be simple, uniform, and resolved. Capitalist progress is confronted with the existence of indigenous peoples and their distinct ways of existing, and the result is a set of relationships, clashes, contradictions, and dystopias. We tried to penetrate this complexity by analyzing three news articles from local digital newspapers, related to situations involving indigenous people. From them, we tried to capture elements that could serve as articulators
\end{abstract}


for the recognition of the geographic context. In this correlation of interests and struggles fought daily in multiple ways, on one side there are people resisting and on the other, there are modernizing forces trying to exterminate or assimilate them. The history of Dourados runs alongside the history of these conflicts, even if hegemonic narratives claim otherwise. Everyday geographical situations show us this. The hegemonic narratives also try to take away from the indigenous people the condition of subjects and imprint them in a passive spatial condition. However, the indigenous people show daily that they still exist today because they have conquered this through space and time, with their strategies, negotiations, mistakes, and successes.

Keywords: Indigenous people; Guarani-kaiowá; Coloniality.

\title{
PUEBLOS INDÍGENAS EN DOURADOS: REFLEXIONES GEOGRÁFICAS A PARTIR DE NOTICIAS DE PRENSA
}

\begin{abstract}
RESUMEN
La ciudad de Dourados - Mato Grosso do Sul, y la región a la que pertenece, son conocidas como graneros del agronegocio. Junto con esta imagen agroexportadora tan aclamada por algunos sectores de la sociedad, hay una serie de realidades que complejizan lo que parece sencillo, uniforme y resuelto. El progreso capitalista se enfrenta a la existencia de los pueblos indígenas y a sus distintas formas de existir, y el resultado es un conjunto de relaciones, choques, contradicciones y distopías. Intentamos penetrar en esta complejidad analizando tres artículos de noticias de periódicos digitales locales relacionados con situaciones que involucran a personas indígenas. A partir de ellos, buscamos captar elementos que pudieran servir de articuladores para el reconocimiento del contexto geográfico. En esta correlación de intereses y luchas trabadas a diario de múltiples maneras, por un lado están los pueblos que resisten y por otro las fuerzas modernizadoras que intentan exterminarlos o asimilarlos. La historia de Dourados corre paralela a la historia de estos conflictos, aunque las narrativas hegemónicas afirmen lo contrario. Las situaciones geográficas de la vida cotidiana lo confirman. Las narrativas hegemónicas también intentan arrebatar a los pueblos indígenas la condición de sujetos e imprimirles una condición espacial pasiva. Sin embargo, los pueblos indígenas demuestran a diario que siguen existiendo porque lo han conquistado en el transcurso del tiempo y del espacio, con sus estrategias, negociaciones, errores y aciertos.
\end{abstract}

Palabras Clave: Pueblos indígenas; Guarani-kaiowá; Colonialidad.

\section{INTRODUÇÃO}

O presente artigo tem o objetivo de propor algumas reflexões geográficas sobre os povos indígenas na cidade de Dourados, no Mato Grosso do Sul. Para isso, tomamos como ponto de partida três notícias recentes de jornais digitais locais relacionadas a pessoas indígenas. A partir dessas notícias, buscamos apreender o limiar das relações socioespaciais entre indígenas e brancos nas situações geográficas explicitadas.

Adiantamos que a complexidade da questão indígena em Dourados e no Mato Grosso do Sul é extrema, pois há uma combinação de inúmeros fatores de diferentes naturezas. Dessa forma, o artigo não deve ser tomado como uma tentativa de leitura geral da realidade local, mas 
como o resgate de elementos presentes nesse "todo complexo" que podem apontar contradições e distopias.

O município de Dourados fica localizado no sul do estado. Economicamente é dependente do agronegócio, mas também se apresenta como um importante centro regional de serviços. A situação fundiária é composta principalmente de latifúndios produtores de comodities. Dourados tem uma grande população indígena, composta majoritariamente, mas não apenas, de Guaraní-kaiowas e Terenas, vivendo na Reserva indígena de Dourados, em acampamentos de retomada, ou mesmo na cidade e beiras de rodovias.

Lembramos que as reflexões que serão propostas aqui partem de sujeitos não indígenas, e que por isso carregam uma lógica de pensamento branca, herança de uma trajetória ocidental, por mais que haja o exercício e a tentativa de romper com esses aspectos enraizados no nosso modo de pensar.

As três notícias que serão apresentadas no artigo são intituladas: Adolescentes $e$ crianças indígenas são resgatadas de trabalho escravo em Itaquiraí; Academia é alvo de críticas após postar foto de indígenas sem máscaras: "essas pessoas podem" e Homem morre atropelado no anel viário em Dourados. Ambos os eventos ocorreram e foram noticiados no ano de 2020.

Apesar de acreditarmos que haja uma responsabilidade de todos os sujeitos envolvidos nas situações das notícias, bem como nos meios de veiculação, não objetivamos propor uma individualização da culpa, pois entendemos ser uma perspectiva rasa que pouco acrescenta no avanço da resolução dos problemas. Isso porque ser "indivíduo" pressupõe que exista uma sociedade da qual ele faça parte - o indivíduo só é indivíduo porque está numa sociedade. Dessa forma o indivíduo é, em certa medida, um agente de reprodução do que a sociedade construiu a partir de suas relações socioespaciais, e isso inclui as perversidades. Obviamente não discordamos que o indivíduo é também um agente que produz o espaço, e não apenas reproduz, tendo assim responsabilidades. Apenas que para essa reflexão, isso não se apresenta como o objetivo.

Pensamos, então, que a perspectiva mais eficaz para tratar essas questões seja através da reflexão sobre a causa socioespacial das problemáticas trazidas até aqui, e não as suas consequências, que acabam sempre resultando na individualização das responsabilidades e consequente punitivismo. Deixamos isso para as instâncias da legalidade ocidental, de toda forma colonial, e dos que se colocam na posição do julgamento pelo moralismo, nas suas 
diferentes formas, através dos dualismos bem/mau, certo/errado, legal/ilegal e assim por diante (SANTOS, 2018).

\section{UMA HISTÓRIA, MUITAS HISTÓRIAS: CONTEXTO GEOGRÁFICO}

A primeira notícia da qual discorreremos trata-se de um fato recorrente na cidade de Dourados. $\mathrm{O}$ atropelamento nas rodovias que cortam e margeiam a cidade são relativamente comuns entre indígenas e não indígenas. O perfil das vítimas é de trabalhadores e trabalhadoras que se deslocam em bicicletas, motos ou a pé, para agroindústrias localizadas nas saídas - ou margens - da cidade. Essas agroindústrias, localizadas estrategicamente para uma boa logística e consequentemente potencialização de lucros, oferecem vagas de emprego com baixos salários para pessoas com pouca qualificação profissional. São usinas, frigoríficos e esmagadoras de soja em sua maioria, com nomes de grandes conglomerados financeiros.

O título da notícia trás: Homem morre atropelado no anel viário em Dourados. Publicada em novembro de 2020, no jornal digital Dourados Agora, a matéria inicia afirmando que se trata de um homem indígena e que o fato ocorreu no Anel Viário Norte de Dourados, entre as rodovias BR-163 e MS-156 (NUNES, 2020, p.1).

No trecho que segue as informações iniciais, o jornal trás outro fato importante para entender o caso, e ao mesmo tempo aspecto presente no contexto de Dourados:

Segundo informações apuradas pela reportagem do site Dourados Agora, o tio da vítima relatou que ele passou o dia inteiro bebendo e estava perambulando pela rodovia, quando acabou sendo atropelado por um carro, em seguida uma carreta que trafegava pelo local também passou por cima do corpo de J.--------- ${ }^{1}$, que teve a cabeça dilacerada devido ao impacto do acidente (NUNES, 2020, p.1).

O álcool está presente no cotidiano da população de Dourados de muitas formas. Além do consumo do álcool pela população, como ocorre em qualquer cidade brasileira, no contexto douradense temos as usinas de álcool que rodeiam a cidade e, com isso, as grandes plantações de cana-de-açúcar, muitas vezes trazendo relações de trabalho bastante problemáticas, como veremos mais adiante. E claro, como podemos ver na notícia, o consumo de bebidas alcoólicas entre os indígenas.

Sobretudo em relação a população indígena, o problema do consumo de álcool ganha outras dimensões, seja pelo fato de que sua dependência é socialmente diferente da dependência do não indígena, seja pela visão distorcida, generalizadora e criminalizadora de que os "índios

\footnotetext{
${ }^{1}$ Optamos por ocultar o nome da vítima que consta na notícia.
} 
são todos bêbados", como muito se escuta por aqui. A relação de alteridade com o Outro indígena fica clara nessa situação, pois o alcoolismo é um problema de origem ocidental, alimentado pela indústria do álcool, e que os brancos introduziram na realidade dos povos indígenas ${ }^{2}$.

Dando prosseguimento a notícia, outro fato recorrente vem à tona. "Agora os policiais levantam informações para identificar quais veículos estiveram envolvidos no acidente, nenhum dos motoristas parou para prestar socorro" (NUNES, 2020, p.1).

A omissão de socorro é um fato muito presente em casos de atropelamento nas rodovias sul-mato-grossenses, principalmente em locais onde sabidamente há presença de indígenas. $\mathrm{O}$ caso noticiado ocorreu numa rodovia na qual limita, por poucos metros, a cidade de Dourados e a Reserva Indígena de Dourados. Não é possível saber se os motoristas tinham conhecimento desse fator e acusá-los sem provas de terem negligenciado a vítima por ser indígena. Todavia, é importante refletir sobre os fatores presentes no ocorrido e a recorrência de casos semelhantes.

Além do fato consumado dos indígenas serem - e não ficarem por diferentes motivos e nem todos - "bêbados", Melià (2015, p. 15) contribui com uma importante reflexão para compreendermos a negligência com pessoas indígenas, ao adentrar em questões históricas e espaciais:

Há também nesse Mato Grosso "do Sul", que preferiu concentrar sua população em poucos centros para deixar livres grandes extensões de terra para o agronegócio de gado, soja e cana, uma história que tem caracterizado e prejudicado a relação da população não indígena com os primeiros habitantes da região, despojando-os, em menos de um século e meio, de seu ser primitivo, enquanto primeiro e primordial, para reduzi-los a uma condição secundária e dependente, tida como irrelevante e como resto (MELIÀ, 2015, p.15).

De fato, desprover os povos indígenas de suas histórias, de seus modos de existir, introduzindo-os às lógicas modernas ocidentais de viver, desde que ocupando sua margem, tem os tornado irrelevantes para os não indígenas. A negligência, dessa maneira, é fruto de um projeto, no qual os povos indígenas não estão nos planos ou, caso estejam, ocupam um posto subalterno.

No que se refere aos distintos modos de existir no espaço, Kopenawa \& Albert (2015, p. 64) elucidam que "os brancos não pensam muito adiante do futuro. Sempre estão preocupados demais com as coisas do momento", criticando à perspectiva produtivista de

\footnotetext{
${ }^{2}$ Sabemos que os indígenas também fazem suas escolhas. Essa afirmação não pretende vê-los como sujeitos que não agem ou reagem por conta própria, apenas que de fato a indústria do álcool é um fenômeno ocidental. Muitos grupos indígenas produziram ou ainda produzem bebidas fermentadas, mas que tem seu uso social diferenciado.
} 
acumulação. Os autores indicam que os não indígenas enxergam a natureza como algo a ser explorada, não considerando o modo de viver dos Yanomami, pois para eles a floresta é vida e fruto do bem viver (KOPENAWA \& ALBERT, 2015).

Apesar de Kopenawa \& Albert (2015) falarem de outro local do Brasil, a partir da cultura Yanomami, os autores trazem grande contribuição para pensarmos a realidade socioespacial douradense. A lógica da exploração da natureza pelo branco, denunciada pelo autor, está diretamente relacionada à impossibilidade dos povos indígenas de re-produzirem suas práticas socioespaciais no Mato Grosso do Sul. Os Guarani e Kaiowá, por exemplo, que correspondem ao maior contingente populacional indígena da região, sempre viveram a partir da pesca, da coleta e da agricultura se deslocando por grandes áreas. Agora esses povos vivem majoritariamente reclusos na cidade de Dourados, na Reserva Indígena, ou resistindo em áreas de retomada, enquanto o agronegócio ocupa vastas áreas de campo para monocultura - soja, cana-de-açúcar, milho - e utiliza a água dos rios, legitimado pela propriedade privada da terra.

Dessa forma, é possível também indagarmos sobre o fenômeno do alcoolismo dentre os indígenas. Em que medida essa realidade está ligada ao fato de que lhes foram tiradas as possibilidades de manterem seu modo de vida?

Haesbaert (2016, p. 327) pode contribuir com essa indagação a partir da ideia de desterritorialização. Para o autor não existe desterritorialização sem um processo de reterritorialização precarizada, pois não há possibilidade de existir sem território. A questão central para se pensar a desterritorialização, é o fato de que essa ocorre de forma forçada, como acontece com a população indígena do Mato Grosso do Sul, deslocada pelo agronegócio. Essa seria a principal diferença em relação aos deslocamentos que ocorrem por motivos mais brandos. Tais deslocamentos mais brandos, ao contrário da desterritorialização, permitem as pessoas se estabelecerem em novo local com as condições básicas para sua existência (HAESBAERT, 2016).

Desterritorializados e reterritorializados sem as condições ideais para existir - materiais e simbólicas -, muitos indígenas aderem as práticas ocidentais. Esse processo ocorre sempre nas margens da sociedade, sem os acessos do modelo urbano moderno, apenas como mão-deobra barata. $\mathrm{O}$ alcoolismo, assim como outros problemas, pode estar diretamente relacionado a vulnerabilidade socioespacial dessa população, acrescido de um sentido de deslocamento dentro das lógicas ocidentais à pouco aderidas. 


\section{QUANDO A PRESENÇA INDÍGENA É BEM-VINDA EM DOURADOS}

As duas notícias subsequentes nos possibilitam pensar que em momentos convenientes os indígenas podem ser "bem-vindos" em Dourados, desde que passem pelo crivo do não indígena, a partir dos seus hábitos e da sua utilidade.

Woortmann (1997), ao trabalhar a ideia de selvagem e a sua associação em diferentes períodos históricos, aponta que houve um momento de divisão do selvagem em dois. $\mathrm{O}$ selvagem monstruoso e o bom selvagem. Em certo momento o bom selvagem foi associado a seres divinos, não humanos, mas em outro foi associado ao selvagem hospitaleiro, manso, receptivo e já humano, sendo essa segunda a perspectiva que mais nos auxilia neste artigo. $\mathrm{O}$ selvagem monstruoso - que não era bom -, por outro lado, era aquele que oferecia riscos, e posteriormente o que oferecia resistência às imposições da figura do sujeito central.

Em Dourados, os indígenas ocupam muitas das vagas de trabalho mais precarizadas, na maioria das vezes em situação de trabalho informal - informalidade essa, por sua vez, muito bem vinda dentro da lógica legalista. Impossibilitados pelo contexto fundiário - grandes latifúndios e a propriedade privada da terra - e urbano de resistir ao trabalho precário a partir de seus modos de viver, acabam sendo obrigados a aceitar trabalhos que a maioria dos não indígenas recusam, ou mesmo receber menos pelos mesmos trabalhos. Seriam esses os bomselvagens do século XXI?

Mas não é isso que iremos discutir aqui. Discutiremos uma fronteira humana ainda mais perversa, a do trabalho análogo a escravidão, como a noticiada pelo jornal digital Midiamax:

Grupo de 24 trabalhadores indígenas da etnia Guarani Kaiowá, incluindo adolescentes e crianças com idade a partir de dois anos, foi resgatado pelo MPT-MS (Ministério Público do Trabalho de Mato Grosso do Sul) em condições de trabalho análogas à escravidão em fazenda de Itaquiraí. Conforme a fiscalização, eles haviam sido aliciados por empreiteiro que ofereceu R\$ 100 por dia para trabalharem na colheita de mandioca (BUREMA, 2020, p.1).

Adolescentes e crianças indígenas são resgatadas de trabalho escravo em Itaquiraí, é o título da matéria na qual está presente o trecho citado acima. Assim como esse caso, vários outros já foram expostos em Dourados e na região, sendo mais comum na colheita de cana-deaçúcar.

A matéria ainda descreve a situação encontrada na fazenda. Três famílias ocupando apenas um alojamento com cômodos pequenos, sem local adequado para preparação e consumo de alimentos, alimentos preparados nos cômodos utilizados para dormir, não fornecimento de equipamentos de proteção para o trabalho e sem carteira assinada. Além disso, todas essas 
condições de aglomeração e higiene favoreciam a proliferação do Novo Coronavírus ${ }^{3}$, e o caso ocorreu no inverno, onde as temperaturas na região são baixas. Os indígenas ainda tiveram que custear o transporte até a fazenda, eram obrigados a pagar aluguel do alojamento e só acessavam os alimentos, inclusive os que colhiam, comprando em supermercados próximos a preços superfaturados (BUREMA, 2020).

Trazemos a questão da fronteira no sentido das relações de alteridade que podem ganhar contornos perversos, como aponta Martins:

Longe de ser o território do novo e da inovação, a fronteira se revela $[\ldots][\ldots]$ o território da morte e o lugar de renascimento e maquiagem dos arcaísmos mais desumanizadores, cujas consequências não se limitam a seus protagonistas mais imediatos. Elas se estendem à sociedade inteira, em seus efeitos conservadores e bloqueadores de mudanças sociais em favor da humanização e da libertação do homem de suas carências mais dramáticas (MARTINS, 1997, P. 13-14).

Por fim, a última notícia escolhida, intitulada Academia é alvo de críticas após postar foto de indígenas sem máscaras: "essas pessoas podem", pode nos mostrar alguns aspectos da visão que a população douradense tem dos indígenas. Notadamente não é a intenção generalizar a 'população douradense' nem os indígenas, mas uma tentativa de buscar objetivamente elementos que baseiam tais visões.

A notícia veiculada no jornal digital O Progresso expõe um fato ocorrido na cidade recentemente - meados de 2020:

Uma academia localizada na região da Vila Progresso foi alvo de críticas nas redes sociais após publicarem a foto de três indígenas, duas delas crianças, andando pelas ruas da cidade sem máscaras.

$\mathrm{Na}$ legenda da publicação, o perfil no Instagram afirmou: "as academias são lugares de proliferação do Covid e precisam estar fechadas para que as pessoas fiquem com suas imunidades bem baixas, porém essas pessoas podem andar de bando sem máscara e se eu não me engano a aldeia estava cheia de Covid" (O PROGRESSO, 2020).

Como sabemos, as academias não tem por objetivo aumentar a imunidade de seus frequentadores, porém não entraremos no mérito. Iremos nos ater as formas como se referenciam aos indígenas em questão e os expõem. A matéria do jornal prossegue descrevendo

\footnotetext{
${ }^{3}$ Pandemia do COVID-19 que ocorre a partir de 2020 a nível mundial, que causou até o momento (18/05/2021) mais de 430.000 mortes no Brasil, segundo dados do Ministério da Saúde. No Mato Grosso do Sul, as populações indígenas foram bastante afetadas, devido a negligência do Estado sobre as condições de vida e ao alto índice de transmissão do vírus. Posteriormente, com a chegada da vacina, o fenômeno das fake-news (notícias falsas) vêm atrapalhando a vacinação entre indígenas, como podemos ver na notícia: https://g1.globo.com/globonews/jornalglobonews-edicao-das-10/video/fake-news-atrapalham-vacinacao-de-indigenas-no-mato-grosso-do-sul9218050.ghtml Acesso em 18/05/2021.
} 
a imagem capturada sem autorização e utilizada pelo perfil da academia para expor as indígenas: "A foto aparenta ter sido tirada de dentro de um veículo e é evidente a expressão de surpresa das vítimas, que foram expostas sem qualquer filtro de imagem (O PROGRESSO, 2020)".

A exposição dos indígenas sem nenhum constrangimento por parte da academia de ginastica e a forma de se referir a 'essas pessoas', demonstram o desprezo que a nossa sociedade tem pelos povos indígenas. Reduzidos a insignificância num processo histórico parcialmente local e recente, como afirma Melià $(2015$, p. 15) ou mesmo fruto da colonialidade nas relações, fato é que os indígenas não são como 'a gente', brancos. Ora são toleráveis se estiverem em conformidade com os hábitos e costumes dos não indígenas, ora são desejáveis se corresponderem as suas expectativas - sendo bons selvagens -, mas nunca como 'a gente'4.

Após a repercussão negativa, a academia removeu a publicação, como consta na matéria do jornal, e se defendeu em nota afirmando que a:

[...] interpretação está equivocada. Denunciei que a aldeia tem vários casos de Covid e o governo não cuida dos indígenas, e tampa buraco fechando academias como se estivesse cuidando. Não vi onde foi falado mal de índios [...] (O PROGRESSO, 2020).

Apesar de afirmar que a interpretação de milhares de pessoas que leram a publicação estava equivocada, a empresa não comentou a forma como se referiu aos indígenas e nem mesmo o fato de terem exposto a imagem dessas pessoas sem a devida autorização.

\section{CONSIDERAÇÕES}

Os povos chamados genericamente de indígenas, no Mato Grosso do Sul ou em qualquer outro lugar, possuem sua própria história. Essa história é produzida a partir de trajetórias de encontros, e dessa forma é sempre uma história de perspectiva, de interesses, de negociações. Massey (2008) faz importante contribuição à geografia ao propor que o espaço seja visto como um espaço aberto, assim como a história precisa ser vista como uma história aberta, pois assim o são. Dessa forma há o reconhecimento de que a história dos povos indígenas nas Américas não é a história dos brancos. Para além disso, perceber a abertura do espaço e do tempo é pressuposto para acreditarmos que o futuro está por ser feito, construído a partir desses

\footnotetext{
${ }^{4}$ Nem pretendemos que sejam como 'a gente'. Não fazemos aqui apologia a falsa ideia de igualdade, que segue numa perspectiva liberal de igualdade de direitos (universais) e deveres. São povos diferentes, com trajetórias distintas. Apenas buscamos refletir a partir das relações que se dão no âmbito do senso comum.
} 
encontros e relações imprevisíveis e não um futuro acabado, já determinado como por vezes parece ser. Nas palavras de Doreen Massey:

[...] imaginar o espaço como sempre em processo, nunca como um sistema fechado, implica insistência constante, cada vez maior, dentro dos discursos políticos, sobre a genuína abertura do futuro. É uma insistência baseada em tentativa de escapar da inexorabilidade que, tão frequentemente, caracteriza as grandes narrativas ligadas a modernidade. As estruturas do Progresso, do Desenvolvimento e da Modernização, e a sucessão de modos de produção elaboradas dentro do marxismo, todas essas pressupõem cenários nos quais as direções gerais da história, inclusive o futuro, já são conhecidas (MASSEY, 2008, p. 31-32).

Começamos as considerações com essa reflexão para externar que, apesar de o artigo tomar, em alguns momentos, caráter quase denunciativo, entendemos que os povos indígenas tem suas autonomias, e não devem ser vistos como inertes, 'coitados' esperando nossa benevolência ou exploração, nem mesmo um lugar nas narrativas ocidentais dos fatos. Se os povos indígenas, assim como do campo e ribeirinhos, entre outros, existem ainda hoje, é causalidade de suas escolhas, estratégias e capacidade de lidar com as situações que foram colocadas a eles. Vê-los como inocentes, sem maldade, e vítimas indefesas da nossa sociedade também tira deles o papel de protagonistas de suas histórias.

Melià, nesse sentido, acrescenta que:

Há uma história de Mato Grosso do Sul que insiste repetidamente que não há história de povos indígenas na região, ou seja, que essas populações, se alguma vez existiram, ou já não estão ali, ou delas só ficaram alguns restos cujo destino seria sua dissolução num conjunto maior que se chama população sul mato-grossense. Estariam condenados a não ser. De outro lado, os povos indígenas afirmam o contrário: que querem ser o que são e que precisamente por isso ainda o são (MELIÀ, 2015, p. 16).

A partir das notícias, que no artigo são três, mas que se multiplicam com o passar do tempo 5 numa Dourados que vive do índio, do agronegócio e da caça ao `progresso`, devemos refletir e nos posicionar frente às relações socioespaciais que tentam negar a existência do Outro na sua materialidade e imaterialidade. Refletir quais relações queremos produzir, que histórias contar, que espaços construir - sempre abertos, feitos dos encontros de diferentes culturas e das negociações que dali surgem (MASSEY, 2008) - e qual o nosso papel nesse processo no qual sabemos existirem forças de grande magnitude interessadas.

\footnotetext{
${ }^{5}$ Muitas notícias semelhantes às utilizadas já foram redigidas desde a escrita deste artigo, em menos de 1 ano. A mais recente da qual tenho conhecimento fala sobre a morte por atropelamento de uma criança indígena de 6 anos de idade. https://www.enfoquems.com.br/morte-de-crianca-indigena-que-foi-atropelada-causa-protesto-emdourados/ Acesso em 23/03/2021.
} 
Não entramos aqui nas discussões que tangem as concepções distintas de natureza que povos indígenas e brancos possuem. Porém, acreditamos que essas discussões podem representar um importante meio de compreender as relações interculturais. Considerarmos que outras culturas possuem outros sistemas de significações e de relações com o meio é fundamental para compreendermos a legitimidade de suas pautas e demandas. Como exemplo podemos pensar seus tekohas, que os não indígenas jamais compreenderão na sua totalidade, porque seu significado amplo se situa em outro sistema de referências.

De toda forma, podemos ver através das situações apresentadas e brevemente discutidas as distopias que se apresentam rotineiramente em Dourados-MS, bem como as contradições que a nossa sociedade produz.

\section{REFERÊNCIAS}

BRASIL. Ministério da Saúde. Painel Coronavírus. Disponível em: https://qsprod.saude.gov.br/extensions/covid-19 html/covid-19 html.html . Acesso em: $18 \mathrm{de}$ maio de 2021.

BUREMA, Danúbia. Adolescentes e crianças indígenas são resgatadas de trabalho escravo em Itaquiraí. Disponível em: https://www.midiamax.com.br/cotidiano/2020/adolescentes-ecriancas-indigenas-sao-resgatadas-de-trabalho-escravo-em-itaquirai . Acesso em: 20 de novembro de 2020 .

HAESBAERT, Rogério. O mito da desterritorialização: do "fim dos territórios" à multiterritorialidade. Rio de Janeiro: Bertrand Brasil, 2016. p. 396.

KOPENAWA, Davi; ALBERT, Bruce. Palavras dadas. . A queda do céu. Palavras de um xamã yanomami. 1.ed. São Paulo: 2015. p.63-66.

MARTINS, José de Souza. Fronteira: A degradação do Outro nos confins do humano. $2^{\mathrm{a}}$ ed. São Paulo: Contexto, 2016, p. 9-21.

MASSEY, Doreen. Parte um: proposições iniciais. . Pelo Espaço: uma nova política da espacialidade. Rio de Janeiro: Bertrand Brasil, 2008. p.29-38.

MELIÀ, Bartomeu. Prefácio. Memória, história e futuro dos povos indígenas. CHAMORRO, Graciela \& COMBÈS, Isabelle (Orgs.). Povos indígenas em Mato Grosso do Sul: História, cultura e transformações sociais. Dourados: UFGD, 2015. p.15-17 
MORALES, Suelen. Morte de criança indígena que foi atropelada causa protesto em Dourados. Disponível em: https://www.enfoquems.com.br/morte-de-crianca-indigena-quefoi-atropelada-causa-protesto-em-dourados/. Acesso em: 14 de maio de 2021.

NUNES, Cristina. Homem morre atropelado no anel viário em Dourados. Disponível em: https://www.douradosagora.com.br/noticias/dourados/homem-morre-atropelado-no-anelviario-em-dourados . Acesso em: 22 de novembro de 2020.

REDAÇÃO, O Progresso. Academia é alvo de críticas após postar foto de indígenas sem máscaras: "essas pessoas podem". Disponível em: https://www.progresso.com.br/sociedade/academia-e-alvo-de-criticas-apos-postar-foto-deindigenas-sem/374262/. Acesso em: 15 de novembro de 2020.

REDAÇÃO, Portal de notícias G1. Fake News atrapalham a vacinação de indígenas no Mato Grosso do Sul. Disponível em: https://g1.globo.com/globonews/jornal-globonewsedicao-das-10/video/fake-news-atrapalham-vacinacao-de-indigenas-no-mato-grosso-do-sul9218050.ghtml. Acesso em 14 de maio de 2021.

SANTOS, B. de Sousa. Para além do pensamento abissal: Das linhas globais a uma ecologia de saberes. in SANTOS, B. de Sousa e MENESES, M. P. (orgs.) Epistemologias do Sul. Coimbra: Almedina, 2018. p. 23-72.

WOORTMANN, Klaas. O Selvagem e a História. Primeira Parte: Os antigos e os medievais. Brasília: Editora Universidade de Brasília, 1997. p.57. 